\title{
Production, Characterization and Cytotoxic Evaluation of Pyocyanin Pigment Extracted from Pseudomonas aeruginosa Isolated from Industrial Soil Resources
}

\section{Indumathi Mullaiselvan', Vijayarani Kanagaraj ${ }^{2 *}$, Baskaran Dharmar ${ }^{3}$, Murugan Balaraman ${ }^{4}$ and Sundaram Meignanalakshmi ${ }^{5}$}

${ }^{1}$ Doctorate Programme of Food Technology, Department of Food Processing Technology,

${ }^{4}$ Faculty of Food safety and Quality assurance, College of Food and Dairy Technology,

Tamil Nadu Veterinary and Animal Sciences University, Chennai, India 600051.

${ }^{2}$ Faculty of Bioinformatics Centre and ARIS cell, ${ }^{5}$ Faculty of Department of Animal

Biotechnology, Madras Veterinary College, Tamil Nadu Veterinary and Animal Sciences

University, Chennai, India 600007

${ }^{3}$ Faculty of Dairy Science, Department of Live stocks Products Technology Madras

Veterinary College, Tamil Nadu Veterinary and Animal Sciences University,

Chennai, India 600007

*Corresponding author

\begin{tabular}{|l|}
\hline Ke y w o r d s \\
Cytotoxic \\
evaluation, \\
Pyocyanin, \\
Pseudomonas \\
aeruginosa \\
Industrial Soil \\
Resources \\
\hline Article Info \\
\hline $\begin{array}{l}\text { Accepted: } \\
\text { 15 February } 2020 \\
\text { Available Online: } \\
\text { 10 March } 2020\end{array}$ \\
\hline
\end{tabular}

\section{A B S T R A C T}

Thirty-five isolates belonging to the various genus of bacteria family were isolated from 25 different soil samples from various industrial areas from different districts of Tamil Nadu. One out of them were identified as P.aeruginosa (P1) and screened for pyocyanin production using submerged fermentation. The Pyocyanin production reached $\mu \mathrm{g} / \mathrm{ml}$ on modified pseudomonas broth. The identification of strain was confirmed by $16 \mathrm{~s}$ rRNA, the similarity with other strains available in the database was 98\% (FDAARGOS_767). P1 was accessed at gene bank with accession number CP041008.1. Identification of the PhzM gene encoding PhzM enzyme was carried out using gene-specific primer followed by PCR. 190bp size gene was amplified using PCR. PhzM gene was confirmed and similarity with (FDAARGOS_767) strain was $100 \%$ in the database. Pyocyanin was extracted by standard chloroform extraction method, purified by HPLC (C17 column) and characterized by UV-Vis absorption spectroscopy, Particle size, zeta potential, FT-IR and LC-MS. The SEM analysis of pyocyanin pigment showed the particle size of microencapsulated pyocyanin. The cytotoxic effect of pyocyanin was investigated using VERO cells and it showed a concentration-response relationship between the concentration and cell viability the cytotoxicity increased gradually with the increase of its concentration. 


\section{Introduction}

Pseudomonas aeruginosa is a gram-negative, aerobic rod shaped bacterium, ubiquitous organism in nature and widespread in soil, water and many other environment. Pseudomonas spp. producing a variety of extracellular phenazine pigments. $P$. aeruginosa was a common environmental gram-negative Bacillus type microbe (Budzikiewicz, 1993).

It was an opportunistic human pathogen as well, was known for its ability to produce pigments. $P$. aeruginosa was widely distributed in the environment; it was founded in soil, water, skin flora, and most man mode environments throughout the world, and had thus colonized many natural and artificial environments (Kerr, 1999).

Majority of P.aeruginosa produce Pyocyanin pigment which was also called as "blue pus". Pyocyanin is a water soluble blue green phenazine nitrogen-containing heterocyclic compound. Pyocyanin is redox active secondary metabolite. It is an extracellular pigment which is produced by Pseudomonas aeruginosa (Lyczak et al., 2000).

Pyocyanin production is abundant in medium with low iron content and plays an important role in iron metabolism. The presence of pyocyanin is easy to detect due to its blue color that turns stationary phase cultures of P.aeruginosa into green color. It has various pharmacological effects on prokaryotic and eukaryotic cell and also used to control phytopathogen. Pyocyanin is a zwitterion at blood $\mathrm{pH}$, it is easily able to cross the cell membrane (Lau et al., 2004).

Pyocyanin usually exists in three different forms oxidized, monovalently reduced or divalently reduced. Mitochondria aids in the convertion of pyocyanin between its redox states, Pyocyanin generates reactive oxygen species and it is because of its redox active state. Pyocyanin generally inactivates Catalase enzyme by reducing the gene transcription and targeting the enzyme. Pyocyanin modulates glutathione which is one of its important characteristics. In particular the pool of the reduced form is depleted while the oxidised form is promoted by hydrogen peroxide which is not mutated by Catalase (O'Malley et al., 2004).

A variety of redox active phenazine compound are produced by strain of P.aeruginosa, including pyocyanin, phenazine 1- carboxylic acid and phenazine 1- carboxamide (Ran et al., 2003). The phenazine based pyocyanin has the ability to generate reactive oxygen species (ROS). It has great role in biosensors as a redox compound for carrying out electron transfer between enzyme molecules and the electrode material (Priyaja, 2013).

The objectives of this study were 1) to isolate pigment producing P.aeruginosa from different soil samples; 2) purify and characterize pyocyanin by standard protocol and techniques; 3) to study the functional activity of pyocyanin.

\section{Materials and Methods}

\section{Sample collection and processing}

Twenty five soil samples were collected at a depth of $15 \mathrm{~cm}$ from different industrial areas at different districts of Tamil Nadu, India and kept in sterile polyethylene bags at $4^{\circ} \mathrm{C}$ until isolation process. Sampling procedures and microbial analysis were carried out according to standard methods (AOAC, 2016). Fifty grams of each soil sample was placed in a $100 \mathrm{ml}$ sterile PBS (1X) solution and shaken at $250 \mathrm{rpm}$ for $2 \mathrm{hrs}$. $1 \mathrm{ml}$ of soil suspension was serially diluted up to $10^{9}$ dilution. $10^{7}, 10^{8}$, 
$10^{9}$ dilutions were plated onto nutrient agar and pigmented colonies were selected and primarily identified by standard biochemical tests including; oxidase, Catalase, nitrate reduction, citrate utilization (O'Malley et al., 2004).

\section{Molecular identification of P.aeruginosa strain and $P h z M$ gene}

The genomic DNA was extracted from the overnight culture using DNeasy® Blood and Tissue kit (Qiagen) as per the manufacturer's instructions and quantified in Nanodrop One (Thermoscientific, USA). The PCR was carried out using 16S rRNA universal primers in a thermal cycler (Veriti, Applied Biosystems). PCR mixture consists of Amplicon master mix $12.5 \mu \mathrm{l}, 1.0 \mu \mathrm{l}$ each primer, $3.0 \mu 1$ of DNA and $7.5 \mu 1$ of nuclease free water. The cycle conditions were initial denaturation at $94^{\circ} \mathrm{C}$ for $3 \mathrm{~min}$ followed by 35 cycles of denaturation at $94^{\circ} \mathrm{C}$ for $1 \mathrm{~min}$, annealing at $56^{\circ} \mathrm{C}$ for $1 \mathrm{~min}$, extension at $72^{\circ} \mathrm{C}$ for $1.3 \mathrm{~min}$ and final extension at $72^{\circ} \mathrm{C}$ for $5 \mathrm{~min}$ (Hoshino, 2011). $10 \mu \mathrm{l}$ of PCR mixture was loaded on to $0.8 \%$ agarose gel to examine the PCR product against $1 \mathrm{~Kb}$ ladder (Thermofisher). The PCR products were purified using MinElute ${ }^{\circledR}$ Gel extraction kit (Qiagen) as per the manufacturer's instructions. The gel eluted PCR products were sequenced (Eurofins, Bangalore). The sequences obtained were then analysed for their homology with the gene sequences in the Genbank. The gene sequences flanking the entire ORF of the selected gene of $P h z M$ were downloaded from NCBI, GenBank (Accession number CP041008.1). Primers used for identifying gene were designed using primer 3 plus software. Polymerase Chain Reaction amplifications were performed using the designed primers. The annealing temperatures of the primers were optimized by gradient PCR. PCR mixture consists of Amplicon master mix $12.5 \mu l, 1.0 \mu l$ each primer, $3.0 \mu \mathrm{l}$ of DNA and $7.5 \mu \mathrm{l}$ of nuclease free water. The cycle conditions were initial denaturation at $94^{\circ} \mathrm{C}$ for 5 min followed by 35 cycles of denaturation at $94^{\circ} \mathrm{C}$ for $1 \mathrm{~min}$, annealing at $59^{\circ} \mathrm{C}$ for $45 \mathrm{sec}$, extension at $72^{\circ} \mathrm{C}$ for $1 \mathrm{~min}$ and final extension at $72^{\circ} \mathrm{C}$ for 7 min (Onbasli and Aslin, 2008). $10 \mu \mathrm{l}$ of PCR mixture was loaded on to $2 \%$ agarose gel to examine the PCR product against 100 bp ladder (Thermofisher). The $16 \mathrm{~S} \mathrm{r}$ RNA primers used in this study were Forward: 5'AGATTTGATCCTGGCTCAG3'; Reverse: 5'GGTTACCTTGTTACGACTT3' and $P h z M$ gene specific primers used in this study were: Forward:5'GCTGCGCGTAATTTGATACA3 Reverse: 5'AGATCTCGAAGGCCACCAG3'

\section{Pyocyanin pigment production}

P.aeruginosa was cultured in 1 litre conical flask containing modified pseudomonas broth containing the following ingredients according Deziel et al., 2004. $20 \mathrm{~g}$ of dextrose (Sigma Aldrich), $20 \mathrm{~g}$ of peptone (Himedia), $10 \mathrm{~g}$ of potassium sulphate (SRL), $50 \mathrm{ml}$ of glycerol, $4 \mathrm{~g}$ of pseudomonas broth (Himedia) and $1.4 \mathrm{~g}$ of magnesium Chloride (SRL). The organism was inoculated at the rate of $10^{9}$ cells and incubated for 2-3 days at $35^{\circ} \mathrm{C}$ under shaking environment. The change in color of the pigment to blush green indicated the pigment production (Sudhakar et al., 2013).

\section{Extraction of pyocyanin}

The change in color of the pigment to blush green indicated the pigment production of pseudomonas. After 3 days of incubation broth was centrifuged (Thermo fisher cooling centrifuge) at $8000 \mathrm{rpm}$ for 10 minutes. The culture supernatants were transferred into conical flasks and extracted with chloroform (1:2) and the aqueous phase was removed. The bottom layer was re extracted with $1 \mathrm{ml}$ of $1 \mathrm{~N} \mathrm{HCl}$ until color change was observed. The extract was fed into rotary vacuum 
evaporator (SARE-T43 Model, SPAN Automation) and heated upto $70^{\circ} \mathrm{C}$ at $80 \mathrm{rpm}$ for $2 \mathrm{hrs}$ to concentrate the pigment and remove ethanol from pigment. The concentrated pigment solution was used as a source of pyocyanin. Pyocyanin was quantitatively assay based on measuring the absorbance of pyocyanin in the acidic form at $520 \mathrm{~nm}$ according to the following equation (Essar et al., 1990).

Concentration of pyocyanin $(\mu \mathrm{g} / \mathrm{ml})=$ O.D $520 \times 17.072$

\section{Purification and characterization of pyocyanin}

The crude pyocyanin pigment stored in sterile containers at $4{ }^{\circ} \mathrm{C}$ was re-dissolved in $10 \mathrm{ml}$ of chloroform and purified using HPLC separation module Alliance 2695 with diodearray detector PDA 2996 (Waters, Millford, USA) were used. Detection was carried out at the wavelength $275 \mathrm{~nm}$. Separation was performed on a chromatographic column Biorad 300SEC-70 10x300 mm, $3 \mu \mathrm{m}$ particle size (California, USA). Linear gradient and flow rate $2 \mathrm{ml} / \mathrm{min}$ were used. Mobile phase A consisted of water/Methanol/trifluoracetic acid (90:5:5) and mobile phase B acetic $\mathrm{acid} /$ water/trifluoracetic acid (5:90:5). The column temperature was set at $47^{\circ} \mathrm{C}$ and injection volume was $10 \mu \mathrm{l}$. Data was set, observed and evaluated by software Empower (Waters, Millford, USA). Purified pyocyanin was eluted with $25 \%$ methanol in chloroform. The eluted fractions were examined by scanning UV-Vis spectrophotometer and fractions having the same $\lambda$-max were collected together. The purified pyocyanin was subjected to spectroscopic analysis. Ultraviolet and visible absorption spectra of purified pyocyanin dissolved in chloroform or $0.1 \mathrm{~N} \mathrm{HCl}$ was recorded over a range of 200 $700 \mathrm{~nm}$. The Bruker IFS66v FT-IR instrument (VERTEX model, Bruker optics, Germany) consists of globar and mercury vapor lamp as sources, an interferometer chamber comprising of $\mathrm{KBr}$ (Potassium Bromide) and Mylar beam was used for determining the functional groups. Liquid chromatographydiode array detection-mass spectrometry (LCDAD-MS) was performed on an Agilent eclipse HP 1100 LC system with a DAD and a $5 \mu \mathrm{XDB}$ C18 column (Phenomenex, Torrance, CA). SZ100 nano partica (Horiba) instrument was used for analyzing particle size and zeta potential of the pigments.

\section{In vitro bioassay (Cytotoxicity)}

Vero cells were sub cultured and split as per the cell ratio. Pigments were diluted into five or ten fold dilution. Each concentration was added in triplicate. Pigments were treated for a defined time period (1-4 hrs). At the end of exposure pigments were removed from the wells and $200 \mu \mathrm{l}$ of fresh medium was added along with $50 \mu 1$ of MTT was added to all the wells. Plates were wrapped in aluminum foil and incubated at $37^{\circ} \mathrm{C}$ for 4 hours. After incubation medium with dye was removed and the formazan crystals were dissolved by adding 200 $\mu 1$ DMSO. Glycine buffer was added to adjust the $\mathrm{pH}$. Absorbance was read at 570nm (Khan et al., 2012).

\section{Results and Discussion}

\section{Isolation of P.aeruginosa from different soil samples}

Pseudomonas aeruginosa is a full lineage bacterium; Proteobacteria class: Gammaproteobacteria; Order: Pseudomonadales; Family: Pseudomonadaceae; Genus: Pseudomonas; Species: aeruginosa (Hassett, 1996). $P$. aeruginosa is a Gram-negative, aerobic (facultative anaerobic), rod-shaped bacterium with unipolar motility. It was identified as an opportunistic pathogen in human. When 
oxygen, nitrate, and nitrite are absent, it is able to ferment arginine and pyruvate by substrate-level phosphorylation (Richard et al., 2008). Soil samples were widely collected from 25 district industrial area from which 35 different bacterial isolates were identified and pigment producing P.aeruginosa (Figure 1) was isolated from soil sample collected from Guindy Industrial estate, Chennai.

The isolated organism was cultured on nutrient agar and observed its biochemical and sugar fermenting ability. Isolated organism was found to utilize dextrose, fructose, trehalose, mannose and glucose (Table 1). P.aeruginosa was found to be a gram -ve rod shaped non - endospore forming motile bacterium which was positive for Catalase, oxidase and other biochemical activity (Table 2). The isolate could produce blue-green pigment on nutrient medium and developed yellow-green fluorescent pigment under UV light $(520 \mathrm{~nm})$. Identification was confirmed by molecular tools and extracted pigments were purified and characterized.

\section{Molecular identification of P.aeruginosa and its $P h z M$ gene}

The 16S rRNA sequence has been used as taxonomic standard for the phylogenies of bacterial species. The $16 \mathrm{~S}$ rRNA gene sequence depicts the differentiation between organisms at the genus level in major phyla of bacteria. The identification of P.aeruginosa strain was confirmed by 16s rRNA, the similarity with other strains available in database was 98\% (FDAARGOS_767). P1 was accessed at gene bank with accession number CP041008.1. Identification of PhzM gene encoding PhzM enzyme was carried out using gene specific primer followed by PCR. 190bp (Figure 2) size gene was amplified using PCR. PhzM gene was confirmed and similarity with (FDAARGOS_767) strain was $100 \%$ in database.

\section{Purification and characterization of Pyocyanin}

The crude pyocyanin (Figure 3) of P.aeruginosa strain was purified using High performance liquid chromatography (C17 column). Pyocyanin was eluted with $20 \%$ methanol in chloroform. The blue color fraction were collected, dried and stored in $20^{\circ} \mathrm{C}$ for characterization. The physicochemical properties of purified Pyocyanin revealed that the pigment was readily soluble in chloroform, $\mathrm{HCl}$. Various other solvents like benzene, hexane, ethanol, diethylether were used to extract pyocyanin from the broth. Complete extraction of pyocyanin was done using chloroform and benzene as they were more efficient in extraction of pyocyanin. The concentration of Pyocyanin was $5.98 \mu \mathrm{g} / \mathrm{ml}$.

The absorbance spectrum of purified Pyocyanin was estimated from 200nm to 800nm using UV-Vis spectrophotometer. The dried Pyocyanin was dissolved in methanol and absorption was estimated. The absorption was maximum at 300, 450 and 730nm (Figure 4). These results were in accordance to the previous research findings of Priyaja, 2013 studied the UV-Vis spectrum of pyocyanin and found its peaks at $201 \mathrm{~nm}, 320 \mathrm{~nm}$ and $718 \mathrm{~nm}$.

The particle size and zeta potential of the pyocyanin was determined using nano particle instrument. The purified Pyocyanin had a particle size of $107.4 \mathrm{~nm}$ (Figure 5) and the zeta potential of the purified Pyocyanin was $19.2 \mathrm{mV}$ (Figure 6). This result was in acceptance to the previous research findings of Lau et al., (2004).

This dried pigmented filtrate was subjected to High performance liquid chromatography to obtain colored metabolite containing fractions. The fractions obtained were subjected to LCMS after combining them. 
Fraction 1-4 was found to contain an intense peak of $\mathrm{m} / \mathrm{z} 477$ which when subjected to LCMSMS showed the fragments with $\mathrm{m} / \mathrm{z}$
478 and 354 which correspond to the structure of Pyocyanin (Figure 7).

Table.1 Sugar fermentation ability of P.aeruginosa

\begin{tabular}{|c|c|c|}
\hline S.No & Sugars & Pseudomonas aeruginosa \\
\hline 1 & Lactose & - \\
\hline 2 & Xylose & - \\
\hline 3 & Maltose & - \\
\hline 4 & Fructose & + \\
\hline 5 & Dextrose & + \\
\hline 6 & Galactose & - \\
\hline 7 & Raffinose & - \\
\hline 8 & Trehalose & + \\
\hline 9 & Melibiose & - \\
\hline 10 & Sucrose & - \\
\hline 11 & L-Arabinose & - \\
\hline 12 & Mannose & + \\
\hline 13 & Inulin & - \\
\hline 14 & Sodium Gluconate & - \\
\hline 15 & Glycerol & - \\
\hline 16 & Salicin & - \\
\hline 17 & Dulcitol & - \\
\hline 18 & Sorbitol & - \\
\hline 19 & Mannitol & - \\
\hline 20 & Adonitol & - \\
\hline 21 & Arabitol & - \\
\hline 22 & Erythritol & - \\
\hline 23 & A-Methyl-D-Glucoside & - \\
\hline 24 & Rhamnose & - \\
\hline 25 & Cellobiose & - \\
\hline 26 & Melezitose & - \\
\hline 27 & A-Methyl-D-Mannose & - \\
\hline 28 & Xylitol & - \\
\hline 29 & D-Arabinose & - \\
\hline 30 & Glucose & + \\
\hline 31 & Sorbose & - \\
\hline 32 & A-Methyl-D-Glucoside & - \\
\hline
\end{tabular}


Table.2 Biochemical tests of P.aeruginosa

\begin{tabular}{|c|c|c|}
\hline S.No & Biochemical test & $\begin{array}{c}\text { Pseudomonas } \\
\text { aeruginosa }\end{array}$ \\
\hline $\mathbf{1}$ & Gram staining & Gram -ve rod \\
\hline $\mathbf{2}$ & Motility test & Motile \\
\hline $\mathbf{3}$ & Endospore staining & Negative \\
\hline $\mathbf{4}$ & Oxidase test & Positive \\
\hline $\mathbf{5}$ & Catalase test & Positive \\
\hline $\mathbf{6}$ & Methyl red test & Negative \\
\hline $\mathbf{7}$ & Urease test & Positive \\
\hline $\mathbf{8}$ & Indole test & Negative \\
\hline $\mathbf{9}$ & Voges proskeur's test & Negative \\
\hline $\mathbf{1 0}$ & ONPG & Negative \\
\hline $\mathbf{1 1}$ & Esculin Hydrolysis & Positive \\
\hline $\mathbf{1 2}$ & Malonate Utilization & Positive \\
\hline $\mathbf{1 3}$ & Nitrate reduction & Positive \\
\hline $\mathbf{1 4}$ & Lysine utilization & Negative \\
\hline $\mathbf{1 5}$ & Ornithine utilization & Negative \\
\hline $\mathbf{1 6}$ & Phenylalanine deamination & Negative \\
\hline $\mathbf{1 7}$ & Citrate test & Positive \\
\hline $\mathbf{1 8}$ & H S production & Negative \\
\hline
\end{tabular}

Table.3 Data represent the mean \pm standard error of the values

\begin{tabular}{|c|c|c|c|c|c|c|}
\hline S.No & Control & $\mathbf{5 0} \mathbf{m g} / \mathbf{m l}$ & $\mathbf{4 0} \mathbf{m g} / \mathbf{m l}$ & $\mathbf{3 0} \mathbf{m g} / \mathbf{m l}$ & $\mathbf{2 0} \mathbf{m g} / \mathbf{m l}$ & $\mathbf{1 0} \mathbf{m g} / \mathbf{m l}$ \\
\hline CC $_{\mathbf{5 0}}$ Values & 0.153 & 0.0956 & 0.117 & 0.133 & 0.139 & 0.141 \\
\hline \% vialibilty & $100 \pm 0.01$ & $62.40 \pm 0.01$ & $76.52 \pm 0.01$ & $86.96 \pm 0.01$ & $91.09 \pm 0.01$ & $92.40 \pm 0.01$ \\
\hline
\end{tabular}

Figure.1 Pseudomonas aeruginosa streaked on nutrient agar medium plate

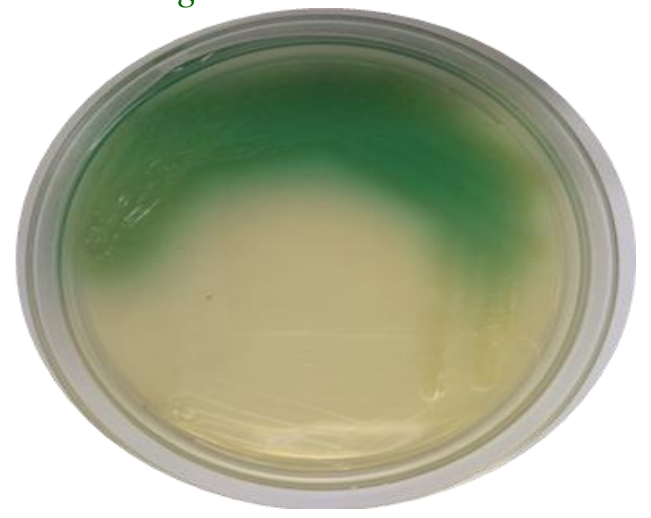


Figure.2 2\% Agarose gel showing PCR amplicon of PhzM primer

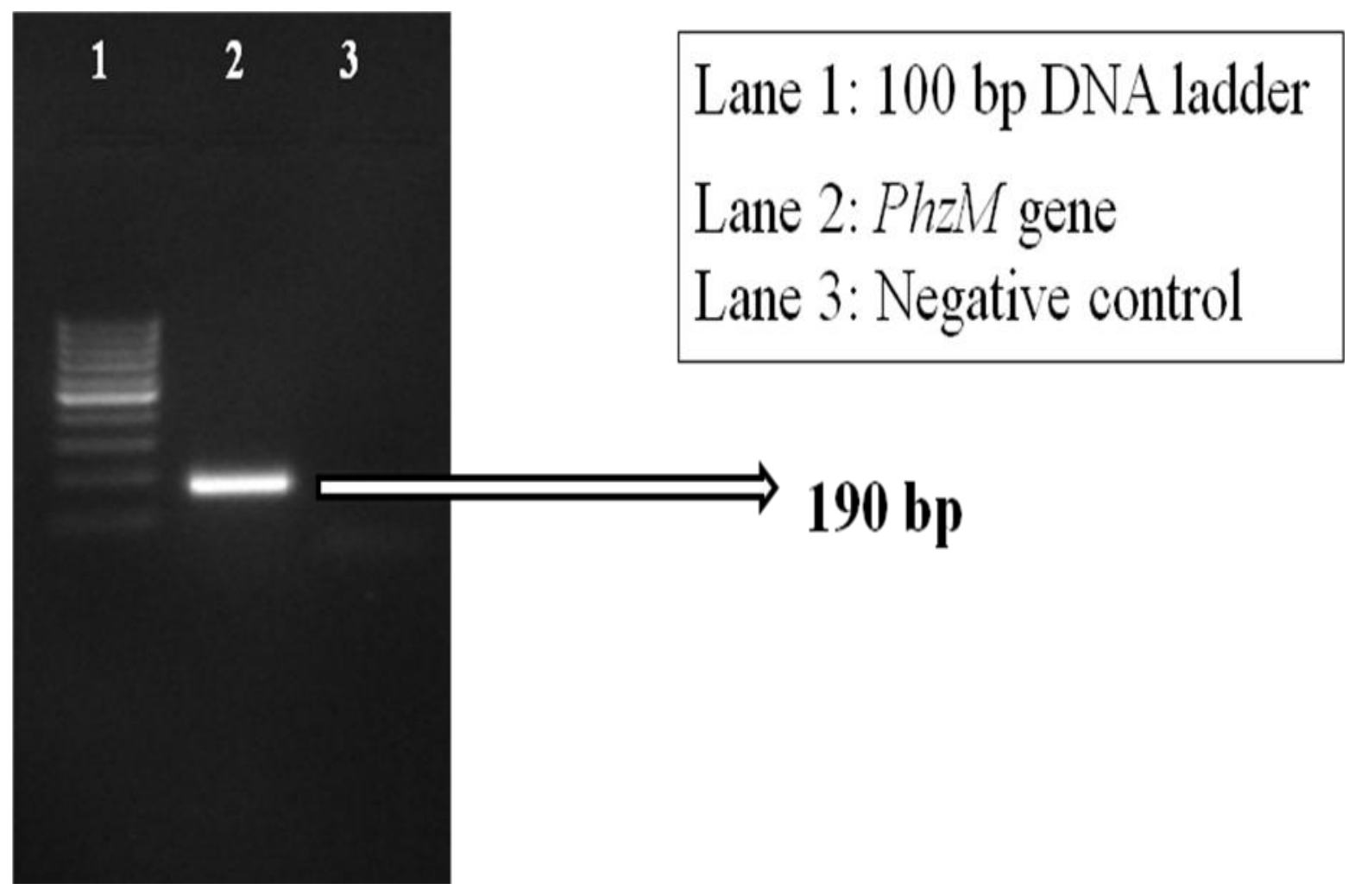

Figure.3 Extraction of crude Pyocyanin pigment
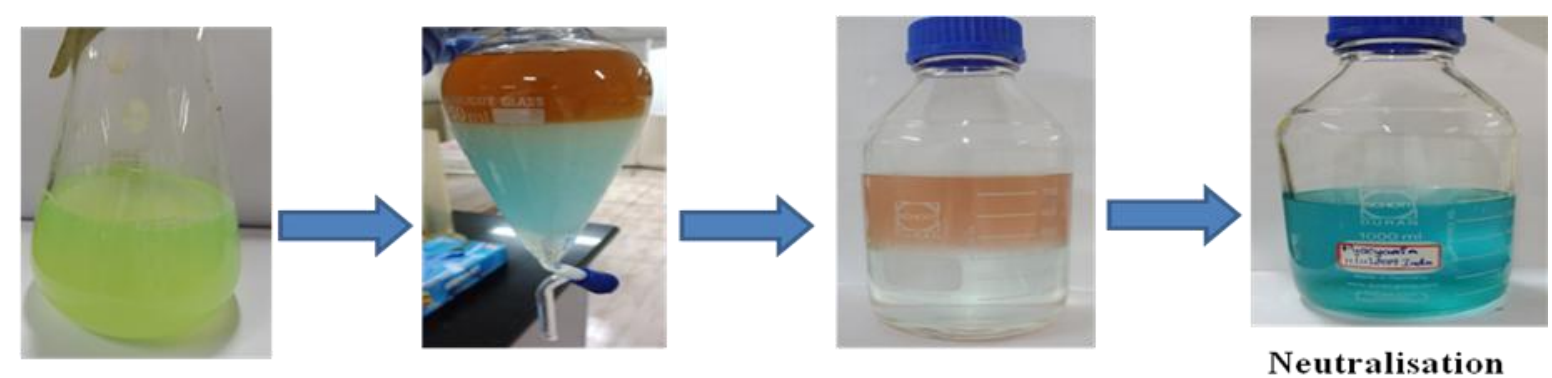

24hrs culture

1:2 Chloroform

$1 \mathrm{~N} \mathrm{HCl}$

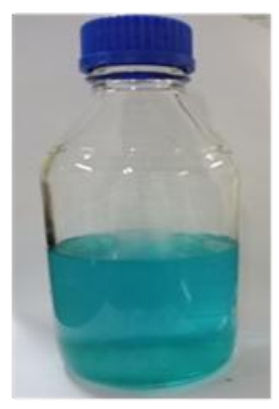

Pyocyanin

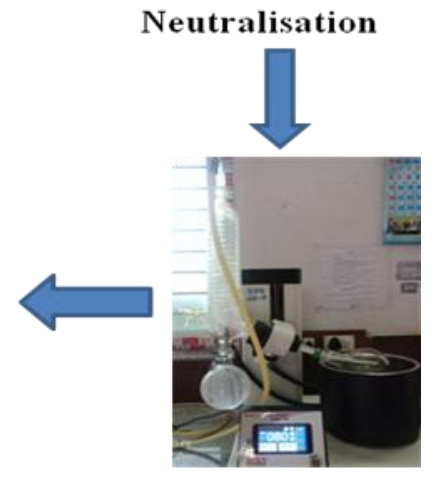

Rotary vacuum Evaporation 
Figure.4 UV-Vis absorption spectrum of purified pyocyanin dissolved in methanol

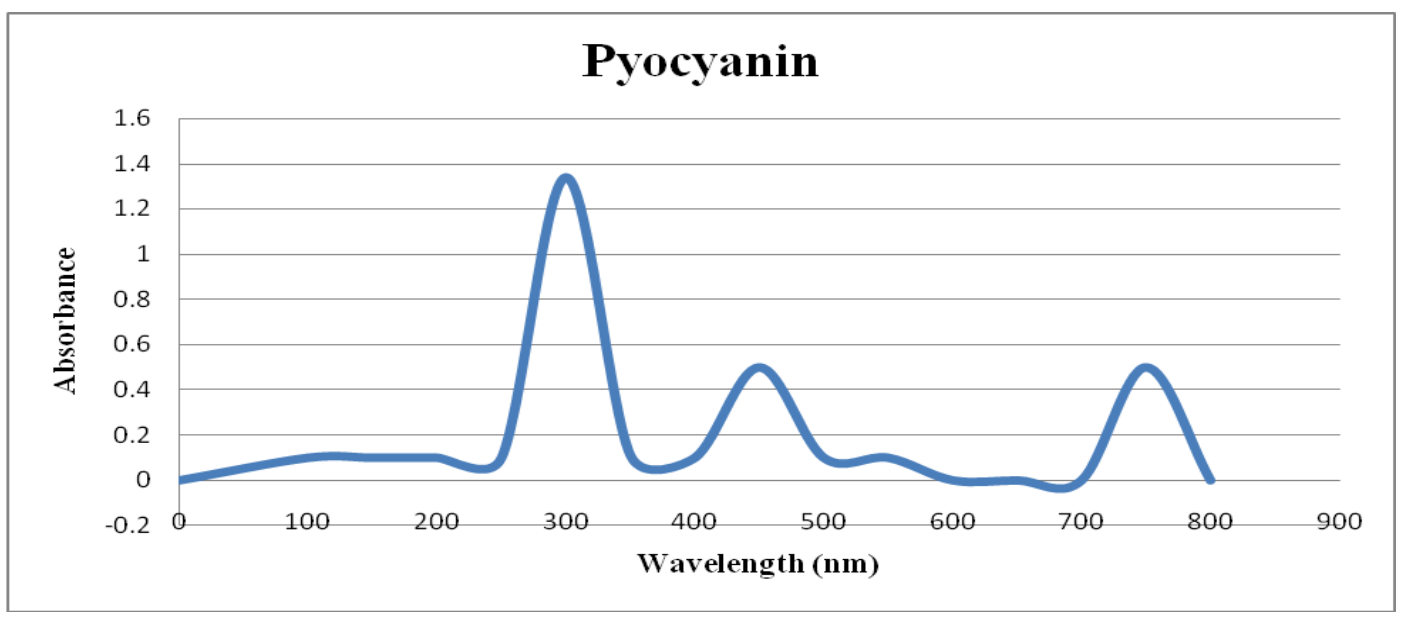

Figure.5 Particle size of purified pyocyanin dissolved in methanol

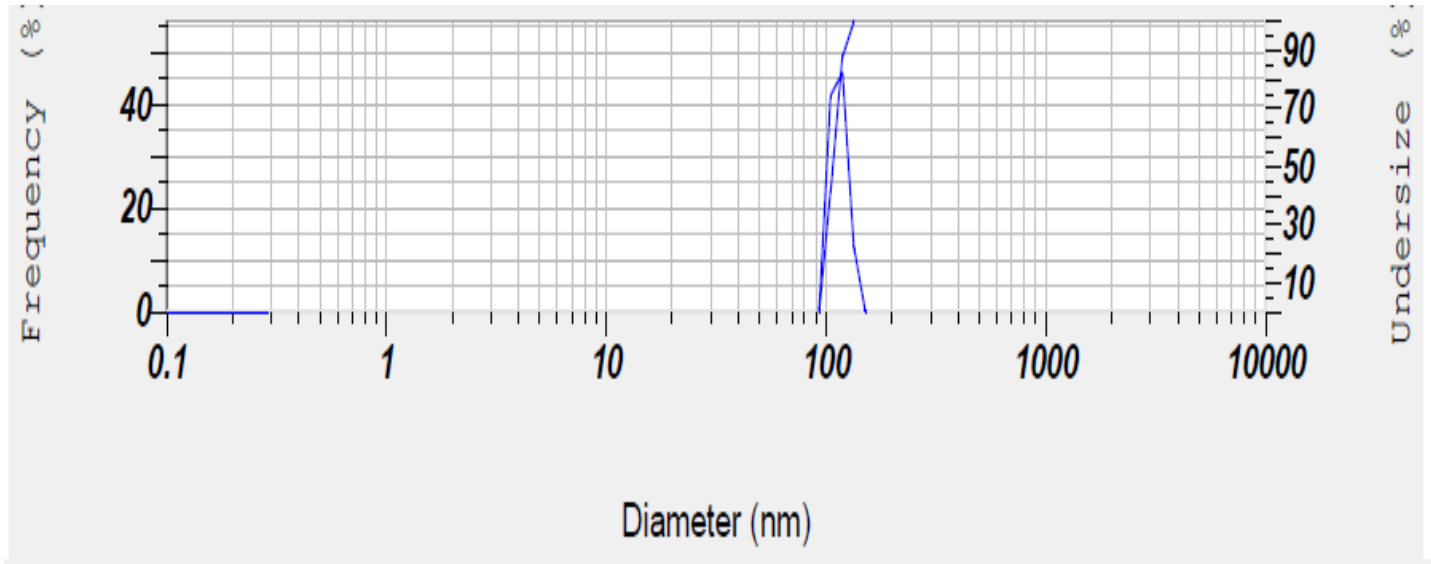

Figure.6 Zeta potential of purified pyocyanin dissolved in methanol

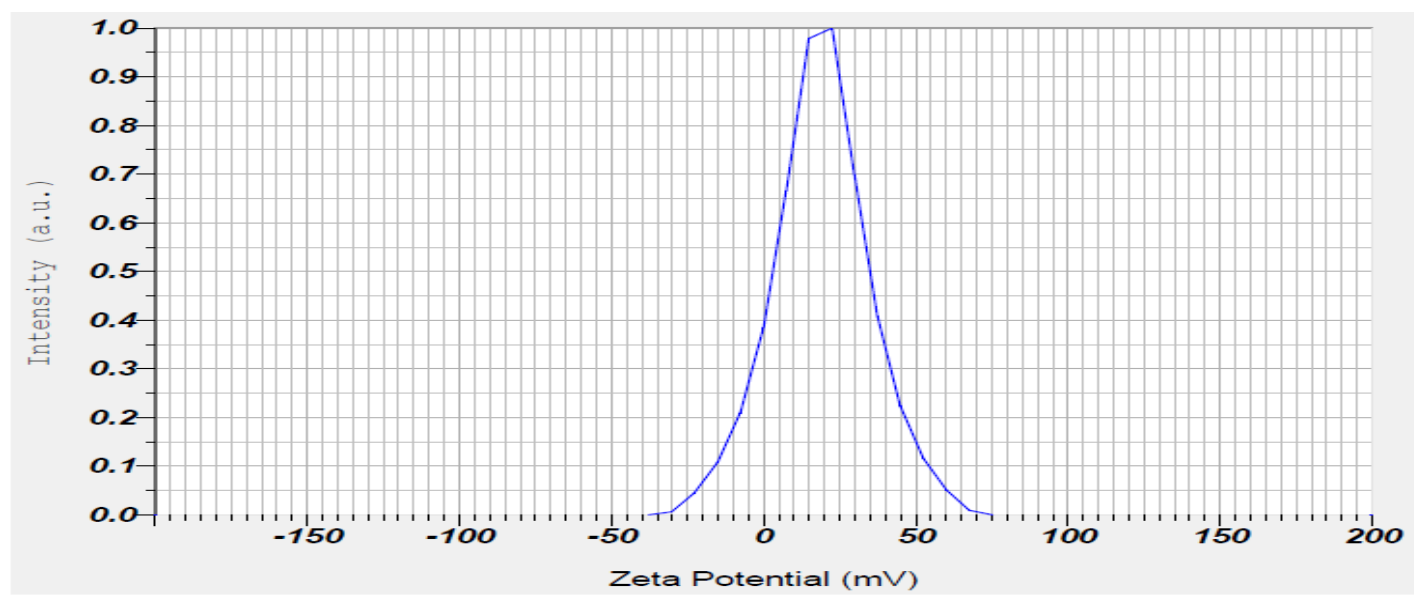


Figure.7 Fragmentation pattern of Pyocyanin (b) (Fraction1-4) (showing an intense peak of m/z 477 and the fragments $\mathrm{m} / \mathrm{z} 478$ and 354 in LCMS)
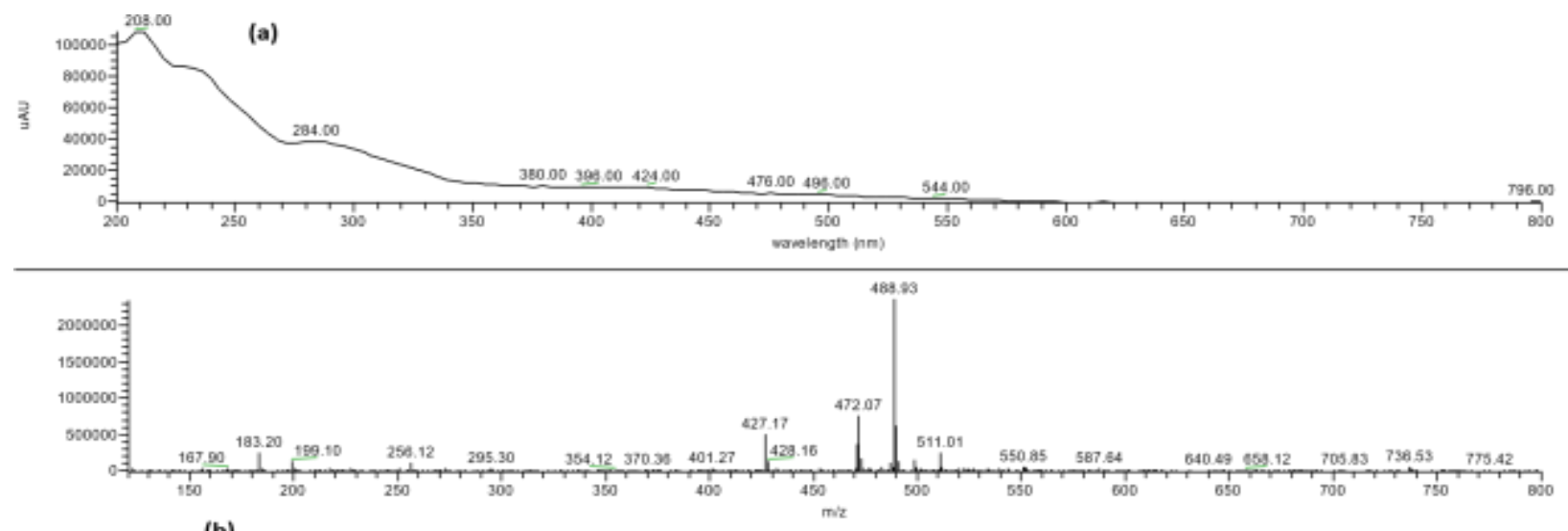

(b)

Figure.8 FT-IR spectrum of purified Pyocyanin

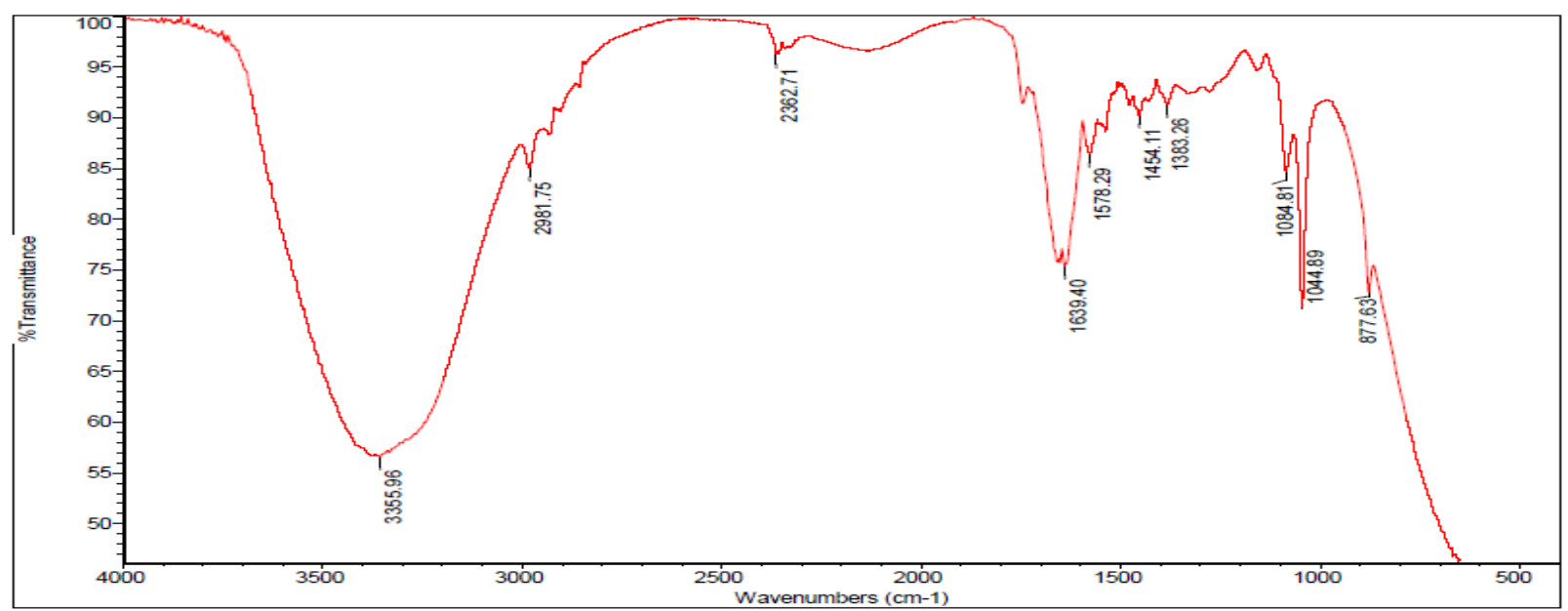

Figure.9 SEM micrographs of pyocyanin

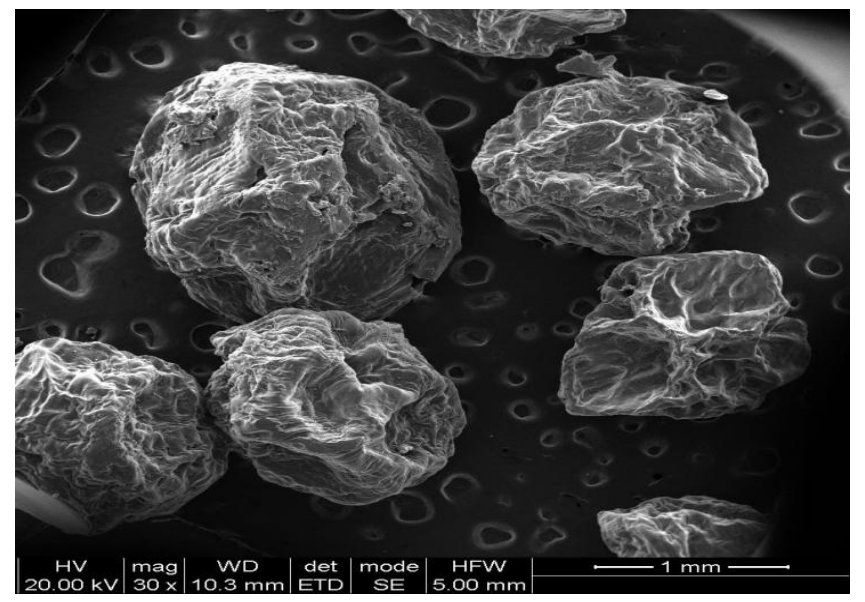


Figure.10 VERO cells treated with Pyocyanin viewed under inverted microscope

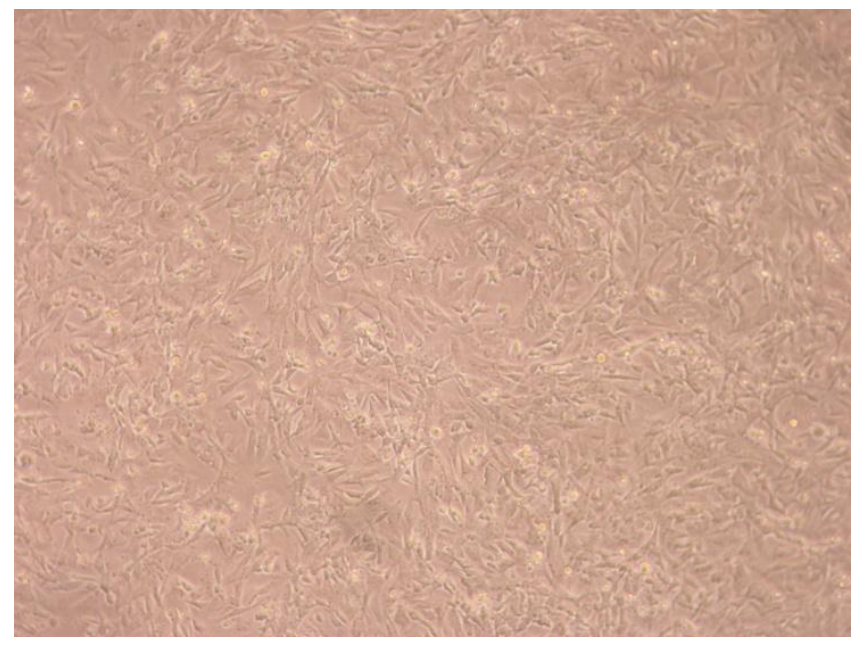

Figure.11 Cytotoxicity of pyocyanin towards cell lines using MTT method

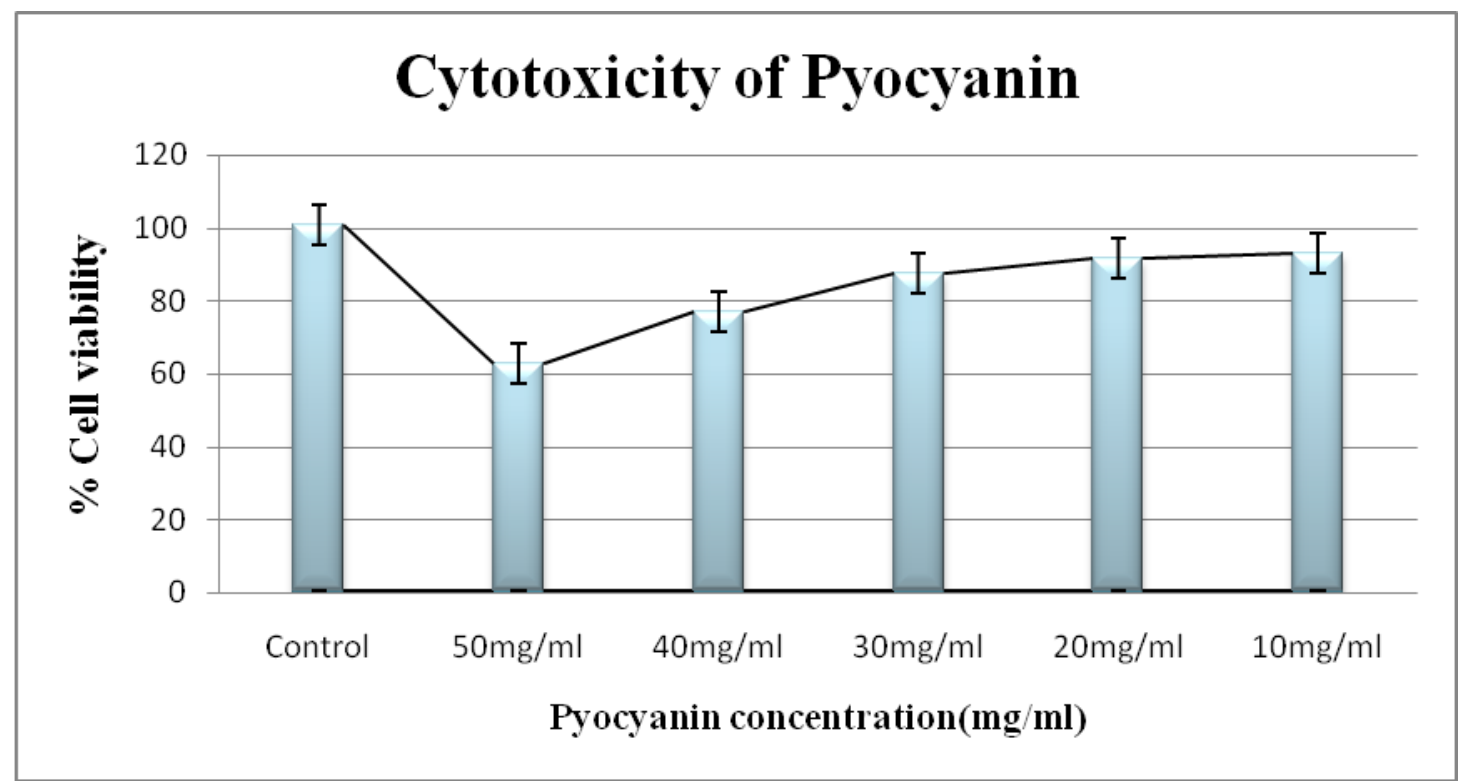

FTIR spectroscopy of the methanolic pigments filtrate was done in order to detect chemical classes of compounds based upon their functional groups present in the cultural filtrate (Fig. 8). In pyocyanin, a peak at $877.63 \mathrm{~cm}-1$ showed $\mathrm{C}=\mathrm{O}$ stretch indicating presence of pyrone of coumarin ring and peaks at $1578.29 \mathrm{~cm}-1, \quad 1639.40 \mathrm{~cm}-1$ corresponded to benzene ring's $\mathrm{C}=\mathrm{C}$ stretch. There was C-H bending peak at $1454.11 \mathrm{~cm}-1$ and $1383.26 \mathrm{~cm}-1$ respectively. $\quad \mathrm{C}=\mathrm{O}$ stretching band at $1044.89 \mathrm{~cm}-1,1084.89 \mathrm{~cm}-1$ and $635 \mathrm{~cm}-1$ in the culture filtrate indicated the presence 1.4-quinones of anthraquinones respectively. The bands at $3355.96 \mathrm{~cm}-1$ ,2362.71 cm-1 and $2981.75 \mathrm{~cm}-1$ corresponded to $\mathrm{C}-\mathrm{H}$ stretch which has been reported in some alkaloids and hydrogen bonded $\mathrm{OH}$ moiety.

The microstructure of Pyocyanin was observed using Scanning Electron 
Microscope (SEM). Examination of the SEM micrographs showed that the particle size of the dried Pyocyanin ranged $100 \mu \mathrm{m}$ to $1 \mathrm{~mm}$. The particle was observed to be in irregular spherical shape with cavities and agglomeration. The agglomeration occurs due to the static electrical force (Figure 9).

\section{In vitro bioassay (Cytotoxicity)}

The reduction of MTT ([3-(4,5dimethylthiazol-2-yl)2,5-diphenyl tetrazolium bromide]) in the cell assesses the functional intactness of mitochondria based on the enzymatic reduction of the tetrazolium salt by the mitochondrial dehydrogenase in viable cells (Denizot and Lang 1986).

MTT and neutral red are probably the most commonly used colorimetric indicators of cell viability and they have been used to evaluate cytotoxicity in a quantitative way in contrast with cell morphology evaluation by inverted light microscopy which is qualitative and more subjective (Smee et al., 2002).

The toxicity of pyocyanin to Vero cells (Figure 10) was investigated by the colorimetric MTT assay. This cytotoxicity was also verified with the cell lines used in this study, and Table 3 shows the \% cell vability values obtained with pyocyanin. Pyocyanin showed a concentration-response relationship since the cytotoxicity increased gradually with the increase of its concentration (Figure 11). The \% cell viability was calculated using the formula.

$\%$ cell viability $=($ Corrected abs. of the sample/Corrected abs. of the control)* 100

\section{Acknowledgement}

The authors deeply thank all the staff of Department of Animal Biotechnology, Madras Veterinary College and Department of Food Processing Technology, Department of Food safety and Quality assurance, College of Food and Dairy Technology for their help in providing facilities for successfully completing this project.

\section{References}

AOAC, 2016. Official methods of analysis the association of official analytical chemists. $20^{\text {th }}$ Ed. Arlington, USA.

Boon, N., De Maeyer, K., Höfte, M., Rabaey, K., and Verstraete, W. (2008). Use of Pseudomonas species producing phenazine-based metabolites in the anodes of microbial fuel cells to improve electricity generation. Applied microbiology and biotechnology, 80(6), 985-993.

Budzikiewicz, H. (1993). Secondary metabolites from fluorescent pseudomonads. FEMS Microbiology Letters, 104(3-4), 209-228.

Essar, D. W., Eberly, L. E. E., Hadero, A., and Crawford, I. P. (1990). Identification and characterization of genes for a second anthranilate synthase in Pseudomonas aeruginosa: interchangeability of the two anthranilate synthases and evolutionary implications. Journal of bacteriology, 172(2), 884-900.

FDA/IFIC. 2000. U.S. Food and Drug Administration, Washington, D.C.

Karpagam, S., Sudhakar, Thukkaram, and Lakshmipathy, Muthukrishnan (2013). Microbicidal response of pyocyanin produced by $P$. aeruginosa toward clinical isolates of fungi. Int $J$ Pharm Pharm Sci, 5(3), 870-873.

Kerr, J. R. (1999). Cell adhesion molecules in the pathogenesis of and host defence against microbial infection. Molecular Pathology, 52(4), 220.

Khan, M. I., Harsha, P. S., Giridhar, P., and Ravishankar, G. A. (2012). Pigment 
identification, nutritional composition, bioactivity, and in vitro cancer cell cytotoxicity of Rivina humilis L. berries, potential source of betalains. LWT-Food Science and Technology, 47(2), 315-323.

Klockgether, J., Cramer, N., Wiehlmann, L., Davenport, C. F., and Tümmler, B. (2011). Pseudomonas aeruginosa genomic structure and diversity. Frontiers in microbiology, 2, 150.

Lau, G. W., Hassett, D. J., Ran, H., and Kong, F. (2004). The role of pyocyanin in Pseudomonas aeruginosa infection. Trends in molecular medicine, 10(12), 599-606.

Lyczak, J. B., Cannon, C. L., and Pier, G. B. (2000). Establishment of Pseudomonas aeruginosa infection: lessons from a versatile opportunist. Microbes and infection, 2(9), 1051-1060.

Malik, K., Tokkas, J., and Goyal, S. (2012). Microbial pigments: a review. Int $J$ Microbial Res Technol, 1(4), 361-365.

Mavrodi, D. V., Bonsall, R. F., Delaney, S. M., Soule, M. J., Phillips, G., and Thomashow, L. S. (2001). Functional analysis of genes for biosynthesis of pyocyanin and phenazine-1carboxamide from Pseudomonas aeruginosa PAO1. Journal of bacteriology, 183(21), 6454-6465.

McKnight, S. L., Iglewski, B. H., and Pesci, E. C. (2004). The Pseudomonas quinolone signal regulates rhl quorum sensing in Pseudomonas aeruginosa. Journal of bacteriology, 182(10), 27022708.

O'Malley, Y. Q., Reszka, K. J., Spitz, D. R., Denning, G. M., and Britigan, B. E. (2004). Pseudomonas aeruginosa pyocyanin directly oxidizes glutathione and decreases its levels in airway epithelial cells. American Journal of Physiology-Lung Cellular and Molecular Physiology, 287(1), L94-
L103.

Onbasli, D., and Aslim, B. (2008). Determination of antimicrobial activity and production of some metabolites by Pseudomonas aeruginosa $\mathrm{B} 1$ and $\mathrm{B} 2$ in sugar beet molasses. African Journal of Biotechnology, 7(24).

Popy, D. M., Kamal, U., Forkan, A., and Mohammed, A. (2017). Extraction, Purification and characterization of pyocyanin produced by Pseudomonas aeruginosa and evaluation for its antimicrobial activity. International $J$ of Biol Res, 6(5), 230-250

Porter RC (2009) Studies in pigment production by Pseudomonas aeruginosa. M.S. thesis, Texas Tech University, TX, $59 \mathrm{p}$

Price-Whelan, A., Dietrich, L. E., and Newman, D. K. (2007). Pyocyanin alters redox homeostasis and carbon flux through central metabolic pathways in Pseudomonas aeruginosa PA14. Journal of bacteriology, 189(17), 63726381.

Priyaja, P. (2012). Pyocyanin (5-methyl-1hydroxyphenazine) produced by Pseudomonas aeruginosa as antagonist to vibrios in aquaculture: over expression, downstream process and toxicity (Doctoral dissertation, Ph. D. Thesis, Cochin University of Science and Technology, India).

Priyaja, P., Jayesh, P., Correya, N. S., Sreelakshmi, B., Sudheer, N. S., Philip, R., and Singh, I. S. B. (2014). Antagonistic effect of Pseudomonas aeruginosa isolates from various ecological niches on Vibrio species pathogenic to crustaceans. Journal of Coastal Life Medicine, 2(1), 76-84.

Rabaey, K., Boon, N., Höfte, M., and Verstraete, W. (2005). Microbial phenazine production enhances electron transfer in biofuel cells. Environmental science and technology, 39(9), 3401- 
3408.

Rahman, P. K., Pasirayi, G., Auger, V., and Ali, Z. (2009). Development of a simple and low cost microbioreactor for highthroughput bioprocessing. Biotechnology letters, 31(2), 209-214.

Ramalho, R., Cunha, J., Teixeira, P., and Gibbs, P. A. (2002). Modified Pseudomonas agar: new differential medium for the detection/enumeration of Pseudomonas aeruginosa in mineral water. Journal of microbiological methods, 49(1), 69-74.

Reddy, N. R., Palmer, J. K., Pierson, M. D., and Bothast, R. J. (1983). Wheat straw hemicelluloses: Composition and fermentation by human colon Bacteroides. Journal of agricultural and food chemistry, 31(6), 1308-1313.

Reyes EA, Bale MJ, Cannon WH, Matsen JM (1981) Identification of Pseudomonas aeruginosa by pyocyanin production on tech agar. J Clin Microbiol 13:456-458

Smedsgaard, J. (1997). Micro-scale extraction procedure for standardized screening of fungal metabolite production in cultures. Journal of Chromatography A, 760(2), 264-270.

Stover, C. K., Pham, X. Q., Erwin, A. L., Mizoguchi, S. D., Warrener, P., Hickey, M. J., Brinkman, F. S., Hufnagle, W. O., Kowalik, D. J., Lagrou, M., Garber, R. L., Goltry, L., Tolentino, E.,
Westbrock-Wadman, S., Yuan, Y., Brody, L. L., Coulter, S. N., Folger, K. R., Kas, A., Larbig, K., Lim, R., Smith, K., Spencer, D., Wong, G. K., Wu, Z., Paulsen, I. T., Reizer, J., Saier, M. H., Hancock, R. E., Lory, S., and Olson, M. V. (2000). Complete genome sequence of Pseudomonas aeruginosa PAO1, an opportunistic pathogen. Nature 406, 959-964.

Sudhakar, T., Karpagam, S., and Shiyama, S. (2013). Analysis of pyocyanin compound and its antagonistic activity against phytopathogens. Int $J$ ChemTech Res, 5, 1101-1106.

Tseng, Y. H., Yang, J. H., Chang, H. L., Lee, Y. L., and Mau, J. L. (2006). Antioxidant properties of methanolic extracts from monascal adlay. Food chemistry, 97(3), 375-381.

Turnidge, J. D. (2015). Susceptibility test methods: general considerations. In Manual of Clinical Microbiology, Eleventh Edition (pp. 1246-1252). American Society of Microbiology.

Vinckx, T., Wei, Q., Matthijs, S., and Cornelis, P. (2010). The Pseudomonas aeruginosa oxidative stress regulator OxyR influences production of pyocyanin and rhamnolipids: protective role of pyocyanin. Microbiology, 156(3), 678-686.

\section{How to cite this article:}

Indumathi Mullaiselvan, Vijayarani Kanagaraj, Baskaran Dharmar, Murugan Balaraman and Sundaram Meignanalakshmi. 2020. Production, Characterization and Cytotoxic Evaluation of Pyocyanin Pigment Extracted from Pseudomonas aeruginosa Isolated from Industrial Soil Resources. Int.J.Curr.Microbiol.App.Sci. 9(03): 2117-2130.

doi: https://doi.org/10.20546/ijcmas.2020.903.242 